Tempo Social; Rev. Sociol. USP, S. Paulo, 10(1): 129-142, maio de 1998.

\title{
Para onde vai a classe média um novo profissionalismo no Brasil?
}

\author{
MARIA LIGIA DE OLIVEIRA BARBOSA
}

\begin{abstract}
RESUMO: Este texto pretende demonstrar que a profissionalização, tanto sob a forma de assalariamento quanto de trabalho autônomo, é ainda uma das possibilidades abertas à classe média brasileira. Os componentes mais importantes do conceito de profissionalismo seriam o controle sobre o trabalho, a capacidade de definição dos problemas e o papel central da educação. Podemos encontrar no Brasil, ao longo do século XX, mas também, e especialmente, nestas últimas décadas, vários indicadores da presença desse profissionalismo.
\end{abstract}

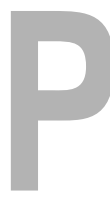

or meio da leitura de jornais, ou da escuta de depoimentos pessoais, poderíamos supor que esta categoria social encaminha-se para extinção muito rápida. Aparentemente a classe média foi o grupo mais atingido pelos processos de mudança pelos quais o país tem passado e as suas formas tradicionais de existência tendem a desaparecer ou, pelo menos, a tornar-se mais precárias.

Para ir além das aparências é necessário examinar com algum cuidado as formas de inserção social que são criadas pelos grupos de classe média ou que se apresentam a eles como possibilidades. Trata-se de analisar os processos de criação de identidades e de formas de representação mediante os quais esses grupos produzem e modelam o seu lugar na sociedade. Como estamos diante de um conjunto muito diversificado de atividades e de relações sociais, é importante deixar claro desde logo que pretendo tratar de um tipo específico de trajetória. $\mathrm{O}$ meu argumento é que a profissionalização é um caminho significativo de organização de estratégias de estratos da classe mé-
UNITERIMIOS profissionalismo, profissionalização, classes médias brasileiras.

Texto integrante da mesa redonda Para onde vai a classe média, organizada pelos GT's Trabalho e Sociedade e Educação e Sociedade, no XX Encontro Anual da ANPOCS, de 22 a 26/10/1996.

Professora do Departamento de Sociologia e Antropologia da UFMG 
dia, e que a representação do mundo social construída a partir do ponto de vista do profissionalismo tende a se tornar dominante como forma de regulação dos trabalhos e das relações sociais em amplos setores do espaço social.

Este argumento será desenvolvido em três partes: inicialmente, uma caracterização teórica do profissionalismo. Em seguida, procurarei mostrar as diferentes faces da profissionalização no Brasil, para, na última parte, analisar algumas das marcas do profissionalismo presentes na nossa sociedade.

\section{Profissionalismo e profissionalização}

Tratado sob os mais diversos aspectos, o processo de profissionalização é considerado como um dos traços mais importantes e distintivos das modernas sociedades ocidentais. Norbert Elias, no seu estudo sobre a sociedade de corte, destaca a mudança resultante da criação de um espaço específico para o trabalho:

Nesta última (a sociedade burguesa) é dentro da esfera profissional que se exerce, em primeiro lugar, a pressão dos constrangimentos sociais e de configuração social. A vida privada é modelada em função de sua dependência com relação à situação profissional.O homem da sociedade burguesa de massa sabe, em geral muito bem, como ele deve se comportar na esfera profissional. Todos os esforços de modelagem da sociedade visam esta esfera. É sobretudo dentro da esfera profissional que a sociedade exerce a sua coerção (Elias, 1985, p. 113-114).

Elias procura destacar aqui a importância da esfera profissional não só como uma das mais centrais nas sociedades modernas, mas principalmente como espaço significativo para constituição de agentes que efetivamente moldem o espaço social, tanto do ponto de vista da sua socialização, quanto da perspectiva de sua ação. Mas podemos encontrar nos trabalhos de autores contemporâneos os elementos teóricos que nos permitem analisar adequadamente o caráter e o significado dessa ação.

Em texto recentemente publicado no Brasil, Eliot Freidson afirma que o profissionalismo é definido por meio das circunstâncias típico-ideais que fornecem aos trabalhadores munidos de conhecimento os recursos através dos quais eles podem controlar seu próprio trabalho, tornando-se, desse modo, aptos a criar e a aplicar aos assuntos humanos o discurso, a disciplina ou o campo particular sobre os quais têm jurisdição (Freidson, 1996, p. 141).

Mantendo-se em sintonia com a produção americana, especialmente as linhas originadas na obra de Parsons, o autor dá ênfase à dimensão 
cognitiva na definição do profissionalismo, ressaltando de maneira especial a autonomia do trabalho profissional. Para Freidson, o principal traço do que ele chama de renascimento do profissionalismo é a persistência de uma característica que já distinguia as corporações medievais: o controle sobre o próprio trabalho (cf. Freidson, 1994). Este é, sem dúvida, um ponto importante. Mais ainda se consideramos o conceito de jurisdição. Segundo Andrew Abbott, jurisdição é o laço que liga um grupo profissional ao seu campo da divisão técnica do trabalho, sendo um conceito que estabelece vínculos mais sociais que propriamente técnicos entre os grupos profissionais e as tarefas por eles desempenhadas (cf. Abbott, 1988). Sob essa ótica, um grupo que realizasse determinado tipo de trabalho só poderia ser considerado uma profissão se estabelecesse jurisdição reconhecida, legitimada, sobre a sua área específica de atuação. Jurisdição, nesse caso, implicaria em controle autônomo sobre esta área.

Talvez em razão do caráter instituidor que o modelo parsoniano teve em ralação às profissões ${ }^{1}$, a crítica à idéia de autonomia profissional em geral, associada ao que se chamou de "ideal de serviço"2 - acabou transformando profissões autônomas em profissões liberais, associando autonomia a trabalho por conta própria. Como se verá a seguir, esta ótica limita as possibilidades de compreensão do fenômeno profissional.

Modelos analíticos weberianos introduziram um conceito fundamental para entender, para além da dimensão cognitiva e da prestação de serviços comunitários, o significado dos processos de profissionalização: poder. (Deve-se notar que Freidson não nega a dimensão de poder no exercício profissional. Como se verá, a novidade dos autores que tratarei a seguir é o caráter relacional da sua utilização.) Em seu belo livro The social transformation of american medicine, Paul Starr (1982) recorre ao conceito de autoridade cultural para explicar o processo pelo qual os médicos americanos constroem o seu lugar na sociedade. Inicialmente, estabelecendo parâmetros comuns de conhecimento e exercício da atividade médica-eliminando charlatões de todo tipo, mas também formas concorrentes de exercício da medicina, como as parteiras e os homeopatas, e gerenciando as escolas médicas -, esses profissionais estendem seu poder para além da sua área própria de trabalho. Isso é feito mediante o controle da alimentação infantil, do estabelecimento de critérios de normalidade em oposição à doença e à loucura, do controle da legislação sobre as empresas privadas prestadoras de serviços de saúde e das políticas publicas nessas áreas, além de outras práticas que tornaram a sociedade americana uma das mais medicalizadas do mundo. Aqui podemos retomar a idéia eliasiana de que a esfera profissional adquire caráter central e se torna a base fundamental para configuração das regras de funcionamento do mundo social. As profissões não só têm controle sobre a sua jurisdição, mas vão além disso: elas procuram dizer como o mundo deve ser.

Neste ponto, o trabalho de Magali Sarfati Larson é de fundamental importância. Esta autora define o profissionalismo como um projeto coletivo
Jean Michel Chapoulie (1973) chama a atenção para o "sucesso" social alcançado pelo modelo parsoniano de profissões que é baseado nos médicos: cada "ocupação" que pretendia obter o status de profissão passou a enfatizar as características apontadas por Parsons como definidoras de uma profissão. Entre essas características podemos destacar o fato de serem praticantes de algum ramo do conhecimento científico ou a busca de autonomia, nas formas definidas abaixo.

2 O estudo de Gyamarti (1975) procura demonstrar como a idéia de autonomia - não se trata propriamente de um conceito, mas de uma noção bastante vaga - é associada à de "ideal de serviço": no modelo por ele criticado, as profissões seriam grupos sociais livres de maiores controles por parte da sociedade porque, além de serem portadores de um conhecimento específico, seriam também dedicados servidores das comunidades nas quais participavam. 
de mobilidade social (Larson, 1977). Nas sociedades contemporâneas criamse novos padrões de desigualdade social, cuja base deixa de ser origem familiar ou outros critérios semelhantes. Nas nossas sociedades torna-se um princípio dominante a idéia de ganhar status via trabalho. Nesse sentido, podemos definir sociedades profissionalizadas como aquelas em que predominam princípios de classificação social baseados no mérito da ocupação. Do ponto de vista de cada profissão, o projeto de mobilidade se traduz numa tendência a monopolizar as oportunidades de renda no mercado de serviços ou de trabalho e também dos privilégios de status e trabalho na hierarquia ocupacional (Larson, 1977, p. 51).

Duas características do processo de profissionalização sobressaem para meu argumento: a importância da educação, especialmente de nível superior, como fundamento de posição social e o papel que as profissões têm na definição e resolução dos problemas enfrentados pelos leigos. Larson salienta o fato de que "o novo critério de estratificação inaugurado pelas profissões depende, portanto, da emergência de um sistema educacional orientado para a moderna divisão do trabalho" (Larson, 1977, p. 70). Desenvolvendo-se sob a forma de universidades e outras instituições de ensino superior, esse sistema se torna elemento fundamental de orientação e alocação dos indivíduos no mercado de trabalho e um dos pilares, ao lado das grandes corporações e do Estado, da estrutura de classificações sociais. O termo credencialismo procura descrever o tipo de sociedade em que os critérios meritocráticos, certificados via diplomas universitários, tornam-se a base mais importante de posicionamento social.

Por outro lado, temos um outro efeito da profissionalização que é a capacidade dos grupos profissionais de definirem, ou redefinirem, os problemas com que lidam os leigos. Paul Starr demonstra esta possibilidade para o caso dos médicos, que é, provavelmente, o mais claro. Na relação médicopaciente ou na participação ativa dos médicos na definição de certas políticas públicas fica evidente o poder profissional. Mas não devemos nos esquecer de outras profissões, um pouco mais modestas, talvez. Engenheiros rivalizam com médicos na definição das condições ergonômicas ideais para os diversos trabalhos. Decoradores, modistas, cabeleireiros, tanto quanto psicólogos, advogados, padres ou engenheiros, ainda que partindo de pressupostos diferentes, apresentam o mesmo traço em comum: a pretensão de dizer qual é o problema do leigo. Evidentemente, a solução também é encaminhada pelo mesmo profissional ou colegas.

Em Larson e Starr encontramos a possibilidade de estender a idéia de controle sobre o trabalho profissional e vinculá-la às relações sociais envolvidas. Trata-se aqui de vincular o conceito de profissionalismo a processos sociais mais amplos, que configuram características fundamentais das sociedades. Agregando os elementos mais importantes tratados, podemos dizer que a profissionalização é um processo pelo qual se estabelece o que Freidson chama de princípio ocupacional (cf. Freidson, 1994, p. 61-74) como base para 
a formação, identificação e hierarquização dos grupos sociais. Com isso, podemos estender o conceito de controle do trabalho para além da esfera puramente organizacional, para o conjunto das relações sociais. É bom salientar que, ainda que o conceito não permita por si só afirmar qualquer coisa sobre o grau de dominância do profissionalismo numa dada conjuntura histórica ou sociedade, ele nos aponta os elementos principais para caracterização de espaços profissionalizados: o controle sobre o trabalho, a capacidade de definição dos problemas e o papel central da educação nos sistemas de estratificação.

\section{As faces do profissionalismo no Brasil}

Numa caracterização tão rápida do profissionalismo como a que foi feita nos parágrafos anteriores não é possível distinguir todas as suas características. Uma delas, bastante importante, é a disputa entre os diversos grupos pelo domínio do espaço profissional. Cada grupo procura moldá-lo à sua imagem e semelhança, segundo os seus próprios princípios, sua linguagem particular. No Brasil não encontramos muita dificuldade, pelo nível dos conhecimentos atuais, em estabelecer os grupos profissionais dominantes ao longo de nossa história recente bem como os respectivos projetos.

Podemos dizer que o processo de profissionalização no Brasil começa com a introdução do que Simon Schwartzman (1987) chamou de saberes modernos como recurso na luta interelites. Certamente que, antes dos engenheiros e sanitaristas, havia no país os advogados. Nossos bacharéis, cuja formação acadêmica foi muito bem caracterizada por Sérgio Adorno (1988), não poderiam, a não ser muito grosseiramente, ser tratados como profissionais. A base de afirmação e de legitimação do seu poder, o ponto de partida da sua atuação não era o seu saber, o seu conhecimento dos meandros da legislação, como ocorre com seus colegas atuais, mas a sua situação de classe, o seu patrimônio familiar de relações sociais e políticas. No máximo, poderíamos aproximá-los das profissões de status (cf. Elliott, 1975), características da Inglaterra até o século XVIII. Nada a ver com as modernas profissões que são base dos atuais sistemas de estratificação.

No início do século, os sanitaristas cariocas destacam-se como portadores do saber científico que pretendia racionalizar a vida de todos os cidadãos, pelo menos do Rio de Janeiro. Em 1902, o presidente Rodrigues Alves transforma em prioridades do seu governo a regeneração da capital federal, conhecida na época como "túmulo de estrangeiros" (cf. Vieira, 1994). Tal regeneração seria feita em duas frentes principais: o novo prefeito do Rio, engenheiro Gabriel Pereira Passos, seria o encarregado da reforma urbana e a reforma sanitária seria feita pelo médico sanitarista Oswaldo Gonçalves Cruz, chefe da Diretoria Geral de Saúde Pública, do Ministério da Justiça. Os dois processos são exemplos históricos muito claros do modo pelo qual as profissões conseguem definir os marcos sobre os quais se organizam relações sociais. A Revolta da Vacina tornou evidente o conflito entre a perspectiva cientí- 
A esse respeito, ver o trabalho de Madel Terezinha Luz (1988), bem como os citados por Vieira (1994) e Belisário (1993). fica e as práticas populares - e não só populares, visto que boa parte dos médicos, em especial os positivistas, tinham uma visão bastante crítica em relação aos procedimentos do diretor de saúde pública. Mas a representação médica das condições saudáveis de vida social interferiu também no trabalho de engenheiros e arquitetos, tanto no planejamento das vias públicas, quanto na definição do formato das casas, das formas de iluminação e arejamento que deveriam ser incorporadas às novas construções ${ }^{3}$.

Nos anos 1950/1960 vamos ter o período áureo dos engenheiros. Num trabalho de instituição que se inicia no final do século XIX, onde devemos destacar a Escola de Minas de Ouro Preto, esses profissionais vão ser os responsáveis pela redefinição das formas de atuação do Estado e pela criação de critérios meritocráticos para alocação de trabalhos em certos setores do Estado. A partir da ocupação de cargos-chave na administração João Pinheiro no governo do estado de Minas Gerais, os engenheiros formados na Escola de Minas gestaram o primeiro empreendimento estatal para intervenção na economia. Foi a primeira experiência brasileira de planejamento estatal, já realizada em moldes bastante próximos do que hoje conhecemos. Um primeiro passo de diagnóstico, o mais completo possível, da situação econômica do Estado, para em seguida construírem estratégias de atuação que incluíam desde a criação de instrumentos mais eficazes de gestão do Estado até a criação de uma cidade industrial (Contagem), passando também pela criação de empresas em setores considerados deficitários, de infra-estrutura (a Cemig, a Usiminas e, mais tarde, a Açominas são os exemplos mais conhecidos desse processo criativo). Mediante uma espécie de acordo, pactuado entre as elites modernizantes e os setores mais atrasados do Estado (cf. Dulci, 1983), os engenheiros mineiros transferem sua criatividade para a capital federal e, especialmente no segundo governo Getúlio Vargas, estendem sua ação para outros setores da economia, destacando-se o seu trabalho no Conselho Nacional de Petróleo, no embrião do que veio a ser a Siderbrás e, mais tarde, no Banco Nacional de Desenvolvimento Econômico (cf. Martins, 1985). Nos setores onde conseguiram ter uma ação eficaz, os engenheiros introduziram novos princípios de classificação social, com ênfase especial para os critérios meritocráticos para organização de carreiras nas empresas públicas. Para isso, introduziram também novos formatos para as empresas sob sua direção, estabelecendo regras modernas para a utilização da força de trabalho. A estrutura organizacional da Usiminas, na época da sua criação, é um exemplo perfeito da perspectiva desses profissionais, e entre as inovações introduzidas por eles podemos destacar o estabelecimento de uma nova proporcionalidade entre trabalhadores manuais e engenheiros, bem como a criação de um setor de pesquisa para o desenvolvimento de soluções técnicas que permitissem racionalizar e economizar na produção (Barbosa, 1993).

O grupo seguinte que pode nos fornecer bons indicadores do trabalho profissional de instituição de padrões específicos de organização das relações sociais é o dos economistas. Filhos diletos dos engenheiros - alguns dos 
nossos economistas mais importantes são engenheiros de origem, mas também várias das escolas de economia foram criadas por engenheiros, como é o caso da UFMG -, esses profissionais tiveram a partir do final dos anos 60 a possibilidade de demonstrar eficientemente a sua perspectiva de como deveria ser o mundo social. Desde o controle quase absoluto sobre o planejamento estatal (o que talvez explique a crença, bastante difundida entre eles, de que basta estabelecer leis economicamente racionais para que elas sejam seguidas pelos agentes dispersos pela sociedade) até a definição do padrão organizacional para as empresas privadas (por exemplo, por meio de exigências formais nesta área para concessão de empréstimos oficiais), os economistas constituíram um amplo leque de elementos reguladores das atividades sociais no Brasil dos anos 70 e 80 . O conhecimento popular dos termos técnicos da ciência econômica, as discussões acirradas em torno de taxas e indicadores, a palpitologia sobre a pessoa que deverá ocupar o Ministério da Fazenda semelhante ao processo de indicação do técnico da seleção brasileira de futebol, são todos indicadores importantes da eficiência e do sucesso dos economistas na busca de definição da sua própria posição no mundo social.

Talvez como efeito perverso da atuação dos economistas (Roberto Campos afirma que todo advogado deveria ter a escultura de um economista num lugar sagrado do seu escritório), mas também como resultado das mudanças produzidas pelo processo de democratização no Brasil, que levou a uma redefinição da legalidade no país - a Constituição de 1988 é o marco mais visível dessas transformações -, os advogados voltaram a ganhar papel de destaque dentro do campo profissional brasileiro. Na sua forma atual de trabalho, com caráter profissional stricto sensu, eles vem realizando, talvez de modo mais destacado, a função prevista por Norbert Elias para a esfera profissional: a de configurar o conjunto das relações sociais. Isso é feito por meio da produção de um novo conjunto de regras legais, pela afirmação de jurisprudências, enfim, pela jurisdicização da vida social, semelhante à medicalização da sociedade americana. Analisando o processo de constituição do Estado francês, Pierre Bourdieu (1994) mostra a importância da concentração do aparelho judiciário, destacando o papel deste grupo profissional na constituição das modernas concepções de legalidade, direitos e deveres de cidadania, bem como a sua força na definição da eficácia prática dessas concepções. Em circunstâncias históricas e sociais bastante diferentes, os advogados brasileiros, no entanto, mostram-se como sérios candidatos a repetir seus colegas franceses.

Mas aqui já estamos entrando na última parte do argumento: as evidências contemporâneas da profissionalização.

\section{As marcas do profissionalismo na sociedade brasileira hoje}

Os conceitos discutidos anteriormente bem como as "histórias" mencionadas nos oferecem os elementos para buscar a construção de evidên- 
cias para o argumento de que há na sociedade brasileira atual um forte e significativo movimento de profissionalização. Antes de discutir cada um deles, seria importante mencionar que todos os argumentos colocados em pauta aqui demandariam pesquisa empírica mais aprofundada que permitisse mensurar as tendências - de estabelecimento por conta própria ou de profissionalização -, o peso de cada uma delas e, sobretudo, as diferenças sociais entre os candidatos a uma ou outra trajetória.

Poderíamos apontar cinco tipos de evidência que favorecem o argumento da profissionalização. Em primeiro lugar, o crescimento do contingente populacional portador de diplomas de curso superior, bem como da dependência em relação aos saber profissional. Em segundo lugar, temos a intensificação da busca de controle do trabalho pelos próprios profissionais. Em terceiro lugar, a reorganização do Estado no Brasil. Em quarto lugar, o tipo de exigência de qualificação demandada pelas empresas atualmente, que reforça o princípio ocupacional. Por último, mas não menos importante, temos o crescimento da PEA de "classe média".

\section{O crescimento do número de "Doutores"}

O aumento do número de pessoas portadoras de diploma de nível superior é bastante conhecido e pode ser comprovado por uma série de dados. Entre 1981 e 1990 a taxa de crescimento da PEA com segundo grau e superior completo foi de $91,46 \%$. Por outro lado, a matrícula em cursos superiores cresceu a uma taxa de $344,64 \%$ no período 60/70, 223,70\% entre 70/80 e $9,53 \%$ entre 81 e 89 . No caso do primeiro grau, o crescimento foi, respectivamente, de 83,75\%, 44,22\% e 22,95\% (cf. Pires, 1995).

A dependência em relação aos saberes profissionais é um pouco mais complicada de ser medida mas podemos encontrar evidência do seu crescimento na medicalização da sociedade brasileira ou na sua "jurisdicização". Não é difícil demonstrar o crescimento das exigências de uso dos serviços de profissionais, médicos, advogados, engenheiros, arquitetos. No caso dos médicos, há uma pesquisa interessante, ainda em fase de produção de relatórios, sobre a medicalização do tratamento de picadas de cobras (cf. Diniz, 1995). Os procedimentos populares para combater o veneno e tratar os seus efeitos foram sendo substituídos, nos últimos 20 anos, por "procedimentos científicos" realizados em hospitais, segundo regras médicas. A população de risco cada vez menos conhece os procedimentos tradicionais, recorrendo em proporções crescentes ao atendimento médico-hospitalar. É interessante observar que não há avaliação de diferentes graus de eficiência dos tratamentos por parte dos entrevistados.

\section{A intensificação da busca de controle dos profissionais sobre seu trabalho}

A busca de reconhecimento oficial da existência da profissão-com todos os efeitos que tem para os profissionais e para o público de clientes pode ser acompanhado nos últimos anos para os casos dos sociólogos, dos 
jornalistas e publicitários, mas também para outras profissões menos visíveis, como é o caso dos farmacêuticos. Trata-se de um tipo de processo que ainda hoje acontece, e que o caso dos jornalistas ilustra bem: depois da lei de reconhecimento definiu-se claramente uma área de trabalhos que só podem ser realizados por pessoas com diplomas desta profissão. Também os advogados são exemplares nesse assunto, pois preparam toda uma série de regulamentações que minuciosamente delimita suas áreas de atuação. E, mais importante, explicitamente procuraram impedir ou, pelo menos, dificultar o funcionamento de certas instâncias jurídicas que dispensariam os serviços desses profissionais, como é o caso dos juizados de pequenas causas.

Há, no entanto, uma outra dimensão, qualitativa e, provavelmente, de difícil mensuração, que podemos ver de forma exemplar no caso dos gerentes. Há evidências fortes, que podem ser vistas nos trabalhos de Grün (1996), Marques (1995) e de Mello (1995), de que os gerentes tem desenvolvido estratégias importantes de profissionalização. Profissionalização que pode ter formas sociais bastante diferenciadas (assalariamento, estabelecimento de carreiras em empresas, consultores etc.), mas que guardam entre si um ponto comum importante: a permanência do princípio ocupacional como critério de identificação social. Eles buscam sempre o reconhecimento do seu trabalho nos moldes profissionais, procuram estabelecer critérios profissionais de avaliação dos pares e até a definição de cursos superiores específicos distintivos do grupo (contabilidade e administração aparecendo como os candidatos mais fortes), bem como a definição de limites jurisdicionais para exercício da profissão (sendo este último o mais complicado, seja pela ausência de diplomas específicos, seja pela inexistência, muito reclamada pelos próprios profissionais, de paradigmas científicos reconhecidos como particulares da profissão).

\section{A reorganização do Estado}

O debate sobre a reforma do Estado tem se intensificado nos últimos tempos, mas não é um assunto propriamente novo. Independentemente das posições de apoio ou crítica aos diversos projetos nesta área, uma característica se destaca: todos eles propõem uma racionalização do funcionamento da máquina estatal baseada em critérios que são fundamentalmente aqueles mostrados por Freidson como componentes do princípio ocupacional. Podemos ver isto na luta pela estruturação das burocracias segundo a lógica dos médicos ou dos economistas, na participação da associação dos engenheiros na discussão sobre a privatização da Petrobrás. Mas é na organização das carreiras do Banco Central, da Receita Federal (Auditores Fiscais do Tesouro Nacional) e nas diversas instâncias do Poder Judiciário que temos exemplos de maior clareza: o processo de delimitação de áreas de jurisdição a partir de um conjunto de conhecimentos específicos em determinados assuntos e o reconhecimento da competência a partir de credenciamento em instituições de ensino superior (é muito interessante observar que, especialmente no caso dos AFTN - concursos mais disputados nos últimos anos no Brasil -, há uma 
4 Novamente aqui podemos encontrar vários trabalhos sobre requisitos empresariais em algumas áreas, mas ainda não temos pesquisa empírica abrangente e sistemática sobre o assunto. exigência apenas da posse de diploma de terceiro grau, condição mínima para inscrição. No entanto, a possibilidade de aprovação está fortemente associada à posse de certos conhecimentos específicos. No caso do último concurso, na área de Direito Tributário, no anterior, na área de Contabilidade). Uma outra característica do princípio profissional presente tanto nas propostas de reforma do estado como nos casos das instituições mencionadas acima é a organização das carreiras e dos seus mecanismos de mobilidade de forma estritamente profissional. Isto é, ascende-se na carreira pela aquisição de conhecimentos e experiência em determinado tipo de trabalho e não mais por tempo de serviço. O princípio profissional, pelo menos nessas áreas, sobrepõe-se ao que poderíamos chamar (com um certo grau de inconsistência, visto que não há uma oposição entre os dois) de princípio estritamente burocrático.

O fato de que, apesar da deterioração de inúmeras carreiras no interior do Estado, os concursos públicos ainda consigam atrair número significativo de candidatos demonstra que a profissionalização através do Estado ainda é uma estratégia importante para os agentes de classe média. O problema que permanece é verificar quais setores dentro dessa classe têm a maior probabilidade de se encaminhar para um ou para outro campo de carreiras.

\section{Os critérios de recrutamento nas empresas}

Há alguns meses a revista Veja publicou uma reportagem sobre o novo perfil dos profissionais desenhado no mercado. Na reportagem são indicadas algumas características que vêm se tornando marca do trabalho profissional no Brasil dos anos 90, e uma delas merece ser analisada porque indica uma diferença interessante para o argumento que aqui se desenvolve. Entre as décadas de 70 e 90 "o grau de escolaridade é sua ferramenta de comando", enquanto que, hoje em dia, "sua performance é sua ferramenta de comando" (cf. Veja, 19/10/94, p. 91) Não se trata de dizer que a escolaridade perdeu importância. O que se alterou é que o ensino superior banalizou-se de tal forma que não é mais critério suficiente de distinção. Não houve uma diminuição quanto às exigências de formação. Elas apenas se tornaram um requisito mínimo e banal. Por outro lado, inúmeras publicações, dirigidas a empresários e executivos, investem grandes quantidades de espaço na apresentação das condições e da necessidade de se fazer cursos de pós-graduação (MBA especialmente) para se obter colocações razoáveis no mercado.

A idéia central aqui é que a escolarização, em especial a de terceiro grau, permanece sendo critério de seleção: mesmo tendo sua importância reduzida, ainda é exigência mínima a posse de um diploma superior para ocupar certos cargos. A este podem ser agregados outros critérios ${ }^{4}$.

\section{O crescimento da PEA de "classe média"}

O crescimento da porção feminina da PEA vem acontecendo no Brasil há décadas, mas nos anos 80 a taxa de aumento da escolarização das mulheres foi especialmente alta para os estratos superiores: o número de mu- 
lheres com segundo grau e curso superior aumentou 105,80\% entre 1981 e 1990. No mesmo período homens tiveram um aumento de $80,89 \%$ e na PEA total o crescimento foi de $91,46 \%$.

Num nível menor de agregação podemos verificar a feminização de certas profissões tradicionalmente masculinas. É visível o aumento da proporção de mulheres entre estudantes de medicina e odontologia em qualquer universidade. Essas mulheres acabam se inserindo no mercado como profissionais, gerando um aumento substantivo dos trabalhadores de classe média na PEA. Trabalhadores que se inserem como profissionais no mercado. Por complicado que seja atribuir a certos trabalhos o status de classe média-como é o caso de muitas das ocupações que se abrem para mulheres, que são quase sempre tarefas administrativas subordinadas -, ainda assim é importante lembrar que tais grupos buscam alguma forma de afirmação profissional. Isto se reflete nas reivindicações quanto aos critérios de delimitação de tarefas e definição de carreiras, na realização de cursos como forma de ascensão e aperfeiçoamento e também na realização de seminários e simpósios, nos moldes daqueles das nossas associações científicas. Atualmente há um movimento entre secretárias - especialmente aquelas vinculadas às estatais, federais ou estaduais - no sentido de criar cursos superiores de secretariado em universidades federais.

\section{Conclusões}

Não há muitas dúvidas sobre o crescimento da dependência da sociedade em relação aos saberes profissionais. Tanto a medicalização quanto a jurisdicização da vida social são visíveis a olho nu, bem como algo que poderíamos chamar de "economicização", se o termo não fosse tão feio.

Algumas mudanças vêm ocorrendo, entretanto, na forma de organização social do trabalho profissional. Para alguns grupos, como os executivos e gerentes de Grün, criam-se alternativas a um dos pilares tradicionais de atribuição de status - universidades, Estado e grandes organizações - : a possibilidade de uma trajetória independente, com novas estratégias de carreira onde o recurso básico não é mais a burocracia da empresa, mas uma posição no mercado como trabalhador independente.

Trata-se de um tipo de trabalho que, mesmo valendo-se de outros recursos, mantém ainda como central o princípio ocupacional: a idéia de que o trabalho profissional seja controlado pelo próprio profissional ou pelo grupo e/ou suas elites.

Assim, o crescimento da PEA de "classe média" não pode ser visto como causa: ele é o resultado visível do trabalho de instituição realizado por um conjunto de grupos com recursos sociais suficientes para tornar suas estratégias eficazes. Assim, vemos profissionais que, de um lado, convencem o público, as empresas e o Estado de que são indispensáveis (para o atendimento de certas necessidades, para a racionalização da produção, do Estado, ou 
porque caminhamos para uma sociedade de serviços etc.) e, de outro, criam mecanismos de exclusão que são parte fundamental da própria definição de profissão. Ou seja, a própria competição no mercado de trabalho, entre os diversos grupos sociais, com diferentes graus de poder na definiç̧ão das regras de posicionamento social, acaba resultando nesse crescimento das posições de classe média, num processo semelhante àquele descrito por Stark (1980) para profissionais americanos no período entre guerras. Segundo ele, "longe de constituírem um conjunto de 'lugares vazios', à espera de serem preenchidos por integrantes de uma 'classe contraditória', os profissionais de classe média tiveram papel ativo na criação e formulação de suas posições, através da elaboração de uma projeto profissional que lhes abriu um novo espaço de classe" (Stark,1990, p. 11).

Visto deste ângulo,o problema não é mais de definir as profissões pela substância da sua atividade ou pela forma legal da relação de trabalho, mas sim de verificar a forma social de controle do trabalho. Ou seja, de que forma e em que medida certos grupos sociais conseguem fechar nichos de mercado e estabelecer as condições de trabalho nos mesmos. E, a partir daí, exercer também algum tipo de poder, modelando formas específicas de relações sociais.

Finalmente, é importante salientar o papel das instituições de ensino superior. No que diz respeito ao tema aqui tratado, duas questões destacam-se: quais são os grupos sociais que ainda se valem da universidade como recurso de posicionamento social? Os processos recentes de reorganização empresarial tem produzido novos formatos para a divisão social do trabalho que não correspondem (?) mais à representação dessa divisão vigente nos cursos das nossas universidades. Como ficaria então o princípio ocupacional? O título universitário passa a ser apenas um título nobiliárquico?

Recebido para publicação em setembro/1997

BARBOSA, Maria Ligia de Oliveira. Where are going the middle classes: a new professionalism in Brazil? Tempo Social; Rev. Sociol. USP, S. Paulo, 10(1): 129-142, may 1998.

UNITERIVS

professionalism, professionalization, middle classes in Brazil.
ABSTRACT: This text aims to show that a new kind of professionalization is still one possible path open to the middle classes in Brazil. The most important components in the concept of professionalism are the control over work, the power of defining problems and situations and the central role of education. One can find in Brazil, during the twentieth century and especially on the last decades, some indicators of this professionalization of the middle classes. 


\section{REFERÊNCIASBIBLIOGRÁFICAS}

Аввотт, А. (1988) The system of professions: an essay on the division of expert labour. Chicago, The University of Chicago Press.

Adorno, S. (1988) Os aprendizes do poder: o bacharelismo liberal na política brasileira. São Paulo, Paz e Terra.

BARbosa, M.L.O. (1993) Reconstruindo as minas e planejando as gerais: os engenheiros e a constituição dos grupos sociais. Campinas, 293 p. Tese (Doutorado). Instituto de Filosofia e Ciências Humanas da Unicamp.

BelisáRIO, S.A. (1993) Médico sanitarista: as muitas faces de uma ocupação. Rio de Janeiro, 210 p. Dissertação (Mestrado). Escola Nacional de Saúde Pública.

Bourdieu, P. (1994) Raisons pratiques: sur la théorie de l'action. Paris, Éditions du Seuil.

Chapoulie, J.M. (1973) Sur l'analyse sociologique des groupes professionnels. Revue Française de Sociologie, Paris, XIV, p. 86-114.

DinIz, Marli. (1995) Os donos do saber: profissões e monopólios profissionais. Rio de Janeiro, 286 p. Tese (Doutorado). IUPERJ.

Dulci, O.S. (1983) As elites mineiras e a conciliação. Texto apresentado na VI Anpocs, Águas de São Pedro (mimeo).

Elias, N. (1985) La société de cour. Paris, Flammarion.

Elliott, P. (1975) Sociologia de las profesiones. Madrid, Ed. Tecnos.

Freidson, E. (1994) Professionalism reborn: theory, prophecy and policy. Chicago, The University of Chicago Press.

(1996) Para uma análise comparada das profissões. Revista Brasileira de Ciências Sociais, São Paulo, 31.

GRÜN, R. (1996) O medo do desemprego e as mudanças no universo simbólico das classes médias brasileiras. In: ReIs, E. \& AlmEIDA, M.H.B.T. \& FRY, P. (orgs.). Política e cultura, visões do passado e perspectivas contemporâneas. São Paulo, Anpocs/Hucitec.

Gyamarti, K.G. (1975) The doctrine of the professions: basis of a power structure. International Social Science Journal, Paris, XXVII: 4.

LARson, M.S. (1977) The rise of professionalism. Berkeley, University of California Press.

Luz, M.T. (1988) Natural, racional, social: razão médica e racionalidade científica moderna. Rio de Janeiro, Ed. Campus.

MARQues, A.L. (1995) Gerenciando profissionais e gerentes: carreira, salário e estabilidade no emprego. Revista Brasileira de Administração Contemporânea, Belo Horizonte, 1(9). 
Martins, L. (1985) Estado capitalista e burocracia no Brasil pós-64. Rio de Janeiro, Paz e Terra.

Mello, M.C.O.L. (1995) Os dramas e as tramas da carreira gerencial. Revista Brasileira de Administração Contemporânea. Belo Horizonte, 1(9).

Pires, E.L. (1995) Metamorfoses e regulação. O mercado de trabalho no Brasil dos anos 80. São Paulo, 342 p. Tese (Doutorado). Faculdade de Filosofia, Letras e Ciências Humanas da USP.

Schwartzman, S. (1987) A força do novo: por uma sociologia dos conhecimentos modernos no Brasil. Revista Brasileira de Ciências Sociais, São Paulo, 2(5).

STARK, D. (1980) Class struggle and the transformation of the labor process: a relational approach. Theory and Society, Dordrecht, 9: 89-130.

(1990) Forçando as grades da jaula de ferro: burocratização e informalização no capitalismo e no socialismo. Revista Brasileira de Ciências Sociais, São Paulo, 13: 07-28.

StARr, P. (1982) The social transformation of american medicine. New York, Basic Books.

VieIRA, C.L. (1994) A Revolta da Vacina. Ciência Hoje, Rio de Janeiro, 18(104): 52-60. 